\title{
Assessing the Impact of Alternative Voting Technologies on Multi-Party Elections: Design Features, Heuristic Processing and Voter Choice
}

\author{
Gabriel Katz • R. Michael Alvarez • Ernesto Calvo • \\ Marcelo Escolar · Julia Pomares
}

Published online: 6 August 2010

(C) Springer Science+Business Media, LLC 2010

\begin{abstract}
This paper analyzes the influence of alternative voting technologies on electoral outcomes in multi-party systems. Using data from a field experiment conducted during the 2005 legislative election in Argentina, we examine the role of information effects associated with alternative voting devices on the support for the competing parties. We find that differences in the type of information displayed and how it was presented across devices favored some parties to the detriment of others. The impact of voting technologies was found to be larger than in two-party systems, and could lead to changes in election results. We conclude that authorities in countries moving to adopt new voting systems should carefully take the potential partisan advantages induced by different technologies into account when evaluating their implementation.
\end{abstract}

Keywords Voting technology $\cdot$ Multiparty systems $\cdot$ Field experiments

Electronic supplementary material The online version of this article (doi:10.1007/s11109-010-9132-y) contains supplementary material, which is available to authorized users.

G. Katz $(\bowtie) \cdot$ R. M. Alvarez

California Institute of Technology, Pasadena, CA 91125, USA

e-mail: gabriel@hss.caltech.edu

E. Calvo

University of Houston, Houston, TX, USA

M. Escolar

Universidad de Buenos Aires, Buenos Aires, Argentina

J. Pomares

London School of Economics, London, UK 


\section{Introduction}

An increasing number of countries around the world have adopted automated voting systems since the 1990s, and many others are currently conducting vote pilot tests (Alvarez and Hall 2008). While the academic literature has focused mainly on the reliability and accuracy of these new technologies (Ansolabehere and Stewart 2005), only few studies have directly examined their effect on election outcomes (Card and Moretti 2007; Herron and Wand 2007). Empirical analyses have even been fewer in multiparty races, where with a larger number of candidates on the ballot, voters may be more likely to resort to shortcuts to identify and select their preferred electoral option (Lau and Redlawsk 2006). Hence, differences in the way in which information is displayed and accessed across technologies could have a considerable effect on vote choice in multiparty systems (Calvo et al. 2009).

In this paper, we examine whether and to what extent information effects embedded in alternative voting technologies can affect the relative support for candidates in multiparty races and alter election results. In order to do so, we conducted a large-scale voting experiment during the 2005 legislative election in Buenos Aires, Argentina, in which almost 14,000 voters in 41 precincts were randomly assigned to different electronic voting prototypes. Our research design has the advantage of mitigating concerns that have plagued previous observational studies in this area, such as vote tampering and endogenous technology adoption (Card and Moretti 2007; Herron and Wand 2007). ${ }^{1}$ To account for differences in the characteristics of the participants and in the treatment assignment across precincts, we combine parametric and non-parametric statistical methods that allow us to assess the robustness of our findings and reinforce the validity of our conclusions.

Our estimates indicate that differences between alternative technologies in terms of what cues are more prominently displayed and how they are presented to voters can systematically favor some parties to the detriment of others. These findings expand and complement previous research on the influence of information effects and cognitive heuristics on electoral outcomes (Bartels 1996; Lau and Redlawsk 2006; Reynolds and Steenbergen 2006) and reveal some unexpected potential consequences of adopting new voting systems. ${ }^{2}$ While our conclusions are based exclusively on data from Argentina, some of the predominant features of the 2005 Buenos Aires legislative races also characterize elections in several other polities. In transitional and less established democracies, especially in Latin America and Eastern Europe, voters usually have to select their preferred choice among multiple competing parties sharing similar labels and relying on diffuse programmatic appeals, thus enhancing the potential influence of information framing on the decision-making process (Calvo et al. 2009). It is among these less developed democracies that the new voting technologies have disseminated more rapidly and extensively in the last decades, with one-third of the countries currently testing

\footnotetext{
1 Although other studies also used experimental designs to assess the impact of different technologies on voter behavior (e.g., Herrnson et al. 2008), none of them focused on their effect on electoral outcomes.

2 Throughout this paper, the term "heuristics" refers to cognitive shortcuts and simplifying rules of thumb individuals resort to in order to make political judgments or inferences with considerably less than complete information about the different electoral options (Lau and Redlawsk 2006).
} 
e-voting systems located in Latin America (Alvarez et al. 2009). Hence, the evidence presented here has relevant policy implications at a time when authorities in many of these countries are considering switching to new voting procedures with little evaluation of their impact on election results and, ultimately, on democratic representation.

The remainder of the paper is organized as follows. The next section briefly reviews the literature on the influence of voting technologies on electoral outcomes, centering on the role of information framing and heuristic processing. We then describe the Buenos Aires pilot project and state the hypotheses to be tested in the empirical part of the paper. Next, we present the approach used to estimate the impact of alternative voting devices on the support for the parties competing in the 2005 legislative election and report the main results of our analysis. We conclude by discussing our findings' implications for the study of voting technology and pointing to possible avenues for future research. Additional descriptive statistics and estimation results are reported in the Appendix and in the Supplementary Materials accompanying this paper.

\section{The Potential Impact of Voting Technologies on Electoral Outcomes: Information Effects, Design Features and Voter Choice}

The spread of automated voting systems throughout the world has sparked an increased interest in the study of new voting technologies and of the political consequences of their adoption (Alvarez and Hall 2008; Herrnson et al. 2008). In the aftermath of the 2000 U.S. presidential election, growing awareness about the vulnerability of these technologies to illegal manipulation has raised concerns about their possible influence on electoral outcomes (Card and Moretti 2007; Herron and Wand 2007). Other scholars have argued that specific technologies might disproportionately affect turnout rates or residual votes among groups of citizens sharing partisan propensities (Tomz and Van Houweling 2003; Herrnson et al. 2008), while still others explained differences in election results across voting systems due to endogenous technology adoption (Card and Moretti 2007; Herron and Wand 2007). Voting technologies, however, may also affect electoral outcomes even if problems related to vote tampering or endogenous adoption of technologies are absent, and after accounting for systematic differences in voters' individual characteristics. In particular, to the extent that alternative technologies may differ in the type of information available to citizens and in the way in which it is displayed, they may influence individuals' decision-making process and vote choice.

The political science literature has long established that voters rely to some extent on shortcuts such as party labels, candidates' ideology, name familiarity or even candidates' appearance to assist them in their electoral choice (Popkin 1991; Mondak 1993). These voting cues contribute to increase individuals' cognitive efficiency, helping them overcome their limitations for processing information and compensating their lack of political knowledge at the moment of deciding who to vote for (Lau and Redlawsk 2006). Political heuristics can also shift individuals' voting patterns by selectively driving their attention towards particular candidates, 
activating their latent political predispositions or even shaping their political judgments (Bartels 1996; Schaffner and Streb 2002). Furthermore, it is not only the specific shortcuts individuals use that influences their voting behavior, but also how these shortcuts are accessed, processed and integrated into the decision mechanism. Scholars have shown that the ease or difficulty of finding particular cues and their relative prominence can affect the nature and quality of the vote (Mondak 1993; Lau and Redlawsk 2006). For instance, political scientists have underscored that several features of the ballot design, such as layouts, colors, symbols, and the order in which candidates are listed, can modify voters' information-acquisition strategies and choice (Reynolds and Steenbergen 2006). In the same direction, usability research on voting technologies has found that slight variations in interfaces and procedures followed to browse political information across different devices may influence users' attitudes and actions (Herrnson et al. 2008).

The relevance of information framing is likely to be enhanced in multiparty elections. Citizens in multiparty systems have to distinguish and choose between a large number of parties and candidates that often exhibit subtle ideological differences and/or share similar labels that cue voters about their platforms. This imposes substantive cognitive demands on the part of voters, who will have strong incentives to follow 'low information' rationality (Popkin 1991). Previous studies have concluded that, as the number of available electoral options increases and the information environment becomes more complex, individuals tend to be more responsive to simple cues that allow them to reduce the time and effort devoted to deciding how to vote (Lau and Redlawsk 2006). The influence of political heuristics will tend to be especially marked in low-information races in which a large number of parties or candidates with ambiguous policy positions compete for the vote of an inattentive citizenry (Mondak 1993; Lau and Redlawsk 2006).

Despite this extensive body of research on the role of cognitive shortcuts in political decision-making, there is very little empirical evidence about the impact that variations in ballot styles and usability features across voting technologies may have on citizens' heuristic-processing strategies and electoral choice. To the best of our knowledge, there is in fact no work addressing this issue in the case of multiparty elections. In this sense, the Argentine voting pilot provided an ideal setting to test for the potential influence of information effects induced by different voting devices. The field experiment took place simultaneously with the 2005 Buenos Aires legislative election, in which 30 (41) parties presented candidates for the national Congress (city legislature), many of them with similar generic names and diffuse policy proposals and ideologies (Amado 2006; Calvo et al. 2009). The prototypes tested in the pilot used different interfaces and presented different information to voters, highlighting particular cues and forcing participants to follow specific search patterns to find their preferred electoral options. Unlike in other laboratory or field experiments (e.g., Herrnson et al. 2008), participants had to choose between actual parties and candidates, allowing us to assess if alternative devices enhance or mitigate partisan advantages present in real world politics and to examine the relevance of information effects across races with different salience levels. 


\section{The Buenos Aires' 2005 Pilot Project}

In 2003, the Government of the City of Buenos Aires assembled a team of political scientists, geographers, and computer scientists and assigned them the responsibility of designing and supervising a field experiment to test four different electronic voting devices. The voting pilot took place during the legislative election held in Buenos Aires in October 2005, which elected members for both the national Congress and the city legislature using a paper-based manual voting system with party-lists displaying the names of the candidates for all offices. Seats were allocated using a PR-D'Hont formula with closed party lists of magnitude 13 for the Congress and 30 for the city legislature.

Three parties captured three-fourths of the vote in the national election and twothirds of the ballots cast in the city race: Frente para la Victoria (FPV), Afirmación para una República Igualitaria (ARI), and Propuesta Republicana (PRO). FPV was a center-left coalition assembled by President Nestor Kirchner, comprising members of the ruling Partido Justicialista (PJ) as well as of non-Peronist sectors. ARI was an opposition party also in the center-left of the ideological spectrum that had gathered considerable support in the previous (2003) presidential election, while PRO was a newly created center-right party. None of the other parties-including the traditional Unión Civica Radical (UCR)—obtained more than 5\% of the vote in any of the two races. ${ }^{3}$

The three main parties spent the highest amounts of money during the campaign for national representatives and accumulated $65 \%$ of the paid political TV advertisement (Buenos Aires Controller's Office, AGCBA 2006). ${ }^{4}$ In addition, their first candidates, Elisa Carrió (ARI), Rafael Bielsa (FPV) and Mauricio Macri (PRO), were notorious public figures who centralized media interest in the election cycle. ${ }^{5}$ According to a study by the media consulting firm Management Press (2005), they received almost $80 \%$ of the radio and TV airtime devoted to the candidates running for Congress (Fig. 1), and were the only ones who participated in the single televised political debate organized prior to the election. Among the remaining candidates, three high-profile candidates, long-term leftist leader Luis Zamora, of Autodeterminación y Libertad (AL), former Minister of Labor and

\footnotetext{
3 A party with over a 100 years of history, the Unión Civica Radical had traditionally been the main contender of the Partido Justicialista. However, after the collapse of its last (coalition) government in 2001, which pushed Argentina on the verge of institutional chaos, UCR was harshly punished by voters. As a result, it lost ground to new political options like ARI and PRO in subsequent elections, especially in Buenos Aires.

4 According to the Buenos Aires Controller's Office (AGCBA 2006), PRO's campaign expenditures totaled 240,000 U.S. dollars, while ARI and FPV spent about 150,000 dollars each. In comparison, UCR's expenditures were below 85,000 dollars, while most of the remaining parties spent substantially less than that.

5 Bielsa was President Kirchner's Foreign Relations Minister at that time. Carrió was a rising political leader who had been a competitive presidential candidate in 2003, and Macri is a famous businessman and was the president of one of Argentina's most popular soccer clubs at that time.
} 


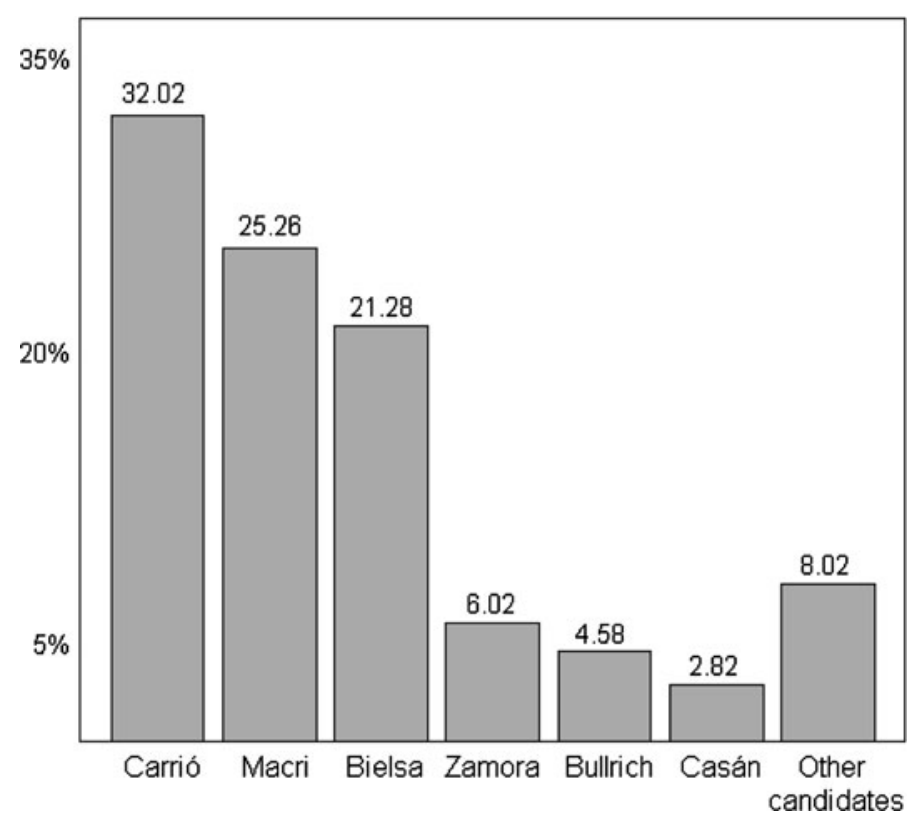

Fig. 1 Distribution of the TV and radio coverage among candidates running for national representatives in Buenos Aires, as percentage of total airtime allocated to the campaign. Source: Management Press (2005) and Amado (2006)

Social Security Patricia Bullrich, of the centrist Unión por Todos (UPT), and media personality Moria Casán, founder and most visible face of the center-right Movimiento Federal de Centro (MFC), received considerable media coverage relative to their parties' meagre electoral support.

A survey conducted by the Universidad de Belgrano (COPUB 2005) in September-October 2005 showed that Macri (PRO), Carrió (ARI) and Bielsa (FPV) were, in that order, the three most widely recognized contenders for a seat in Congress. When asked to name 4 of the aspirants for office, more than $83 \%$ of the respondents selected the candidates of ARI, FPV and PRO. Zamora (AL), Bullrich (UPT) and Casán (MFC) gathered almost $12 \%$ of the mentions, while less than $5 \%$ of the respondents named any of the other hundreds of candidates for Congress. The survey also revealed that a large proportion of the citizens remained apathetic and uninformed even as Election Day approached. More than 39\% of the respondents could not bring four candidates to mind, and almost $73 \%$ did not recall a single policy proposal made by any of the parties (COPUB 2005). While virtually no pre-electoral poll surveyed citizen's opinions about the election of city legislators, it is reasonable to assume that average interest and information levels were even lower in this case. The city election was much less publicized than the national one, with less than $6 \%$ of the political ads on radio and TV featuring any of the competing candidates (AGCBA 2006). As a result, voters knew very little about these candidates at the moment of casting their vote (Calvo et al. 2009). 


\section{Experimental Design and Procedures}

The field experiment was conducted in 41 precincts distributed throughout Buenos Aires, covering about $6 \%$ of the total number of wards (700) in the city. The selected precincts were chosen so as to guarantee a large and diverse pool of potential subjects.

Two weeks before the election, an information campaign-consisting of paid advertisements in the local media, street signs and letters sent to eligible voterswas mounted to make citizens acquainted with the pilot test. On Election Day, test site workers approached voters in each precinct after they had cast an official ballot, handed them a brochure and asked them to participate in a mock election. If a voter agreed to participate, she was directed to an election desk, where poll workers assigned her to one of the four prototypes (treatments) tested in the experiment. To avoid long queues and reduce waiting times, the workers were instructed to allocate participants to each machine successively. The participant was then walked through a 5-min orientation session specific to the device she was about to use, after which she was sent to a voting booth and requested to cast a ballot for each legislative race. Upon completion of the vote, which took on average less than $2 \mathrm{~min}$, subjects were required to provide basic socio-demographic information. A quarter of them also answered a longer exit poll with questions about their patterns of political participation and usability issues specific to each device.

The number of participants totaled 13,876 out of roughly 175,000 voters in the precincts in which the test was conducted. Given that subjects were recruited immediately after the real election, it might be reasonable to assume that they could have just sought to replicate the vote they had already cast. If that had been the case, election results in the experiment would have merely mirrored the official outcomes, rather than reflect the influence of information effects associated with the devices tested. ${ }^{6}$ However, voting patterns in the pilot were in fact clearly different from those in the official election. This can be seen in Fig. 2, which plots the vote-shares of different parties competing in the national and city races. ${ }^{7}$

Of course, we cannot rule out the possibility that these discrepancies may stem from differences between the characteristics of the participants and those of the general electorate. In this sense, the data in Table 4 in the Appendix indicates that, while the distribution of the subjects by age and gender was similar to that of the population of eligible voters, participants in the pilot tended to be more educatedand thus, probably more politically "sophisticated" and interested-than the average voter. Besides this potential sample selection bias, the fact that participants knew that they were being studied might have led them to-willingly or not-alter their voting behavior (Lau and Redlawsk 2006). ${ }^{8}$ Hence, even though including a

\footnotetext{
${ }^{6}$ We thank an anonymous referee for bringing this point to our attention.

7 The percentages in Fig. 2 do not take blank ballots into account. The category "Other parties" in Fig. 2 includes 23 parties competing in the election of national representatives and 34 in the election of city legislators. Figures S.1-S.3 in the Supplementary Materials provides further details about the distribution of parties' vote-shares across prototypes and precincts both in the pilot and in the official election.

${ }^{8}$ For instance, some participants may not have had strong incentives to pay attention during the information session or to avoid voting errors, while others could have changed their choice-e.g.,
} 


\begin{tabular}{|c|c|c|c|c|c|c|c|c|}
\hline \multirow[b]{3}{*}{$\begin{array}{c}\text { Prototype } 1 \\
\text { (party cues) }\end{array}$} & \multicolumn{7}{|c|}{ Election of national representatives } & \multirow{2}{*}{$\begin{array}{l}\text { Other } \\
\text { parties }\end{array}$} \\
\hline & ARI & FPV & PRO & UCR & AL & MFC & UPT & \\
\hline & 22.5 & 16.5 & 22.9 & 5.2 & 2.8 & 2.7 & 0.4 & 32.3 \\
\hline $\begin{array}{c}\text { Prototype } 2 \\
\text { (candidate \& party cues) }\end{array}$ & 20.8 & 17.1 & 24.6 & 4.9 & 3.2 & 3.2 & 1.1 & 29.9 \\
\hline $\begin{array}{l}\text { Prototype } 3 \\
\text { (candidate cues, Ittle } \\
\text { cognitive savings) }\end{array}$ & 19.5 & 13.3 & 18.9 & 5.1 & 2.9 & 2.6 & 1.8 & 41.0 \\
\hline $\begin{array}{c}\text { Prototype } 4 \\
\text { (party cues) }\end{array}$ & 20.3 & 14.9 & 28.6 & 6.0 & 3.6 & 3.4 & 1.4 & 27.8 \\
\hline $\begin{array}{l}\text { Official } \\
\text { election }\end{array}$ & 23.1 & 21.6 & 35.8 & 2.3 & 3.7 & 2.0 & 2.4 & 16.6 \\
\hline
\end{tabular}

\begin{tabular}{|c|c|c|c|c|c|c|c|c|}
\hline \multirow[b]{3}{*}{$\begin{array}{l}\text { Prototype } 1 \\
\text { (party cues) }\end{array}$} & \multicolumn{8}{|c|}{ Election of city legislators } \\
\hline & ARI & FPV & PRO & UCR & AL & MFC & UPT & parties \\
\hline & 19.1 & 13.7 & 21.0 & 5.1 & 2.6 & 2.4 & 0.5 & 40.7 \\
\hline $\begin{array}{c}\text { Prototype } 2 \\
\text { (candidate \& party cues) }\end{array}$ & 17.6 & 13.2 & 20.5 & 5.4 & 2.4 & 2.1 & 0.4 & 43.7 \\
\hline $\begin{array}{l}\text { Prototype } 3 \\
\text { (candidate cues, ittle } \\
\text { cognitive savings) }\end{array}$ & 17.2 & 10.1 & 17.1 & 4.8 & 2.8 & 2.4 & 0.7 & 49.7 \\
\hline $\begin{array}{l}\text { Prototype } 4 \\
\text { (party cues) }\end{array}$ & 18.3 & 12.6 & 27.6 & 5.9 & 3.2 & 3.0 & 1.1 & 34.1 \\
\hline $\begin{array}{l}\text { Official } \\
\text { election }\end{array}$ & 20.7 & 19.2 & 33.0 & 2.3 & 3.5 & 1.9 & 2.2 & 19.5 \\
\hline
\end{tabular}

Fig. 2 Average vote-shares of the parties in the experiment and in the official election. The gray solid circles are proportional to the fraction of the votes for national representatives (upper panel) and city legislators (lower panel) obtained by the each of the competing parties in the precincts in which the pilot was conducted, both among participants assigned to the four prototypes tested and in the official election

rich set of observables and resorting to model-selection techniques could help increase the external validity of the results, care must still be taken when extrapolating conclusions drawn from experimental settings with voluntary participation to the general population (Levitt and List 2007).

That said, Fig. 2 also reveals substantial disparities in the support for some of the parties between the four devices tested, suggesting that the participants might in fact have been responding to differences in the characteristics of the prototypes rather than simply replicating their vote in the official election. Randomization of the subjects across the prototypes guarantees that treatment assignment was independent of their characteristics "except by random chance" (Ho et al. 2007, p. 206), ensuring the internal validity of causal inferences drawn from this sample. Consequently, we examine the effect of the prototypes on the voting behavior of the experimental

Footnote 8 continued

selecting sure losers instead of casting a strategic vote. These problems are virtually unavoidable in mock elections. Nevertheless, survey responses showed that a sizeable proportion of the participants were concerned that the pilot results would be used as an exit poll and took the task of deciding who to vote for quite seriously. 
subjects. Even with the caveats mentioned before about the generalizability of the results from this analysis, it can still shed light on the potential electoral impact of information effects embedded in alternative technologies. ${ }^{9}$

\section{Characteristics of the Prototypes: Designs and Information Cues}

The four voting devices tested in the pilot differed not only in the type of heuristics they stressed, but also in the relative accessibility of these voting cues and in the information-processing demands they imposed on voters (Fig. 2). ${ }^{10}$

Prototype 1 was a direct recording electronic (DRE) design with two separate modules. After users inserted a plastic "smart card" in the first module, a screen presented them with a list of parties' names, logos and numbers. ${ }^{11}$ To view the list of candidates for each party, the voter needed to enter the three-digit party number using a keypad, which was also used to navigate through the screen and to register the vote. If the voter recalled the names of her preferred candidates but did not know their party affiliation, she would need to access each party's list until finding these candidates. Thus, this prototype highlighted party-centric information. After casting her ballot, the participant would remove the smart card from the first module and insert it into the second one, recording her vote and finishing the process.

Prototype 2 was also a touch-screen DRE machine that primed voters using both party- and candidate-centric cues. Once the participant activated the system by inserting a smart card into the reader, the name of the first candidate of each party appeared prominently on the screen, together with the party's name, number and logo. The complete list of candidates was displayed on a second navigation level, once the voter had selected a party by tapping onto the screen. After the subject had chosen an option, a voter verifiable paper trail was printed and deposited behind a glass screen. ${ }^{12}$ For the two DRE devices, the placement of the party labels on the screen was randomly rotated, preventing order effect from benefitting the same party between races.

Prototype 3, which closely resembled the voting system used in the real election, was an optical scan (OS) device with separate paper ballots for each party and election. Just as in the official election, the ballots were spread out on tables placed

\footnotetext{
9 In this sense, Levitt and List (2007) note that, even though experimental results may not translate exactly to real world settings, they can provide relevant information about the underlying mechanisms that may be at work when certain data patterns are observed.

${ }^{10}$ Figure S.4 in the Supplementary Materials depicts the four types of devices tested in the experiment.

${ }^{11}$ In Argentina, parties are assigned an official number which is often used for advertising during the electoral campaign, especially in the case of parties - such as UCR - that have kept the same number over time.

12 Providing one of the DRE devices with a verifiable paper trail allowed us to test its effect on subjects' trust in the accuracy of the voting technologies. The rate of positive answers to a survey item asking participants whether they believed that their vote had been correctly recorded was similar for Prototypes $1(92.1 \%)$ and $2(94.0 \%)$, with no statistically significant effect of the paper trail on the perceived reliability of the machines.
} 
inside the voting booth following the numbering of the parties. ${ }^{13}$ These ballots displayed each party's name, logo, and identification number, as well as the complete list of candidates for each race. The names of the first candidates appeared in larger print than the other information about the parties, so Prototype 3 stressed primarily candidate-centric features. In order to identify their preferred candidates, though, users had to go through the stacks of papers and find the correct ballot for each race, after which they would introduce it into a rolling scanner. As is usually the case in the official elections, ballots rapidly mixed in the booth, complicating the search for voters' favorite candidates.

Finally, Prototype 4 was also an OS device with a single ballot for the two legislative races. After receiving the ballot, voters recorded their preferences for each race using a special marker and introduced it into a scanner located next to the election desk. These ballots displayed the names and numbers of all the parties, in increasing order by the party numbers. The information about the candidates (names and party affiliation) was presented in a separate booklet, also sorted according to the parties' numbers. Survey data showed that participants could easily find their preferred party on the ballot, but had more trouble locating the candidates in the supplementary booklet. Hence, as Prototype 1, Prototype 4 also primed voters using mainly party-centric cues.

For each prototype, subjects voted for national representatives first and for city legislators second, with no straight-ticket option. All devices allowed voters to review the selected ballots and asked them to confirm their choices at the end of the process, preventing over and under-counts. Participants could nonetheless cast blank ballots, so they were not forced to vote for a party in any of the races.

\section{Hypotheses}

Given that very few empirical studies have addressed questions about the impact of alternative voting technologies on electoral outcomes, we draw on the more general literature on the influence of cognitive heuristics and information effects to formulate five hypotheses to be tested in the empirical section of the paper.

The information displayed to voters was overwhelming, including 71 party names, $\log$ os and numbers and approximately 1,600 candidate names for the two legislative races under study. Consequently, based on the arguments outlined above, differences between prototypes in terms of what cues were more noticeable and how they were presented could have had a strong influence on individuals' information processing strategies and voting behavior. In order to explore this issue, Table 1 summarizes participants' responses to a series of survey questions included in the longer exit poll inquiring into the number and the types of political heuristics they used when deciding their vote.

The data shows that the vast majority of the participants relied on only one or two of the available cues to facilitate their vote decision, with party labels and candidates' names being the most frequently used. This is in accordance with Lau

\footnotetext{
13 Ballots of the same party were stacked on top of each other, and the piles corresponding to the different parties were laid out on the tables next to each other, following the official list numbers.
} 
Table 1 Indicators of participants' heuristic-processing strategies across prototypes

\begin{tabular}{llllll}
\hline \multicolumn{1}{c}{$\begin{array}{l}\text { Prototype } \\
1 \text { (party cues) }\end{array}$} & $\begin{array}{l}\text { Prototype 2 } \\
\text { (candidate } \\
\text { and party cues) }\end{array}$ & $\begin{array}{l}\text { Prototype 3 } \\
\text { (candidate cues, } \\
\text { little cognitive } \\
\text { savings) }\end{array}$ & $\begin{array}{l}\text { Prototype } 4 \\
\text { (party cues) }\end{array}$ & $\begin{array}{l}\text { All } \\
\text { prototypes }\end{array}$ \\
\hline Number of candidate- and party-centric cues used & & & \\
Zero & 3.3 & 2.1 & 6.6 & 4.8 & 3.9 \\
One & 62.9 & 58.8 & 63.9 & 67.7 & 61.9 \\
Two & 22.0 & 27.9 & 20.9 & 18.5 & 23.7 \\
More than two & 11.8 & 11.2 & 8.6 & 9.0 & 10.5 \\
Type of cues used ${ }^{\mathrm{b}}$ & & & & 53.2 & 49.3 \\
Party name & 51.1 & 50.7 & 44.3 & 45.3 & 44.3 \\
First candidate's name & 33.5 & 50.2 & 47.3 & 28.4 & 25.3 \\
Party number & 35.4 & 21.1 & 19.9 & 7.4 & 25.8 \\
Party logo & 27.3 & 30.3 & 22.4 & 6.3 & 4.6 \\
Other & 4.1 & 2.7 & 7.5 & 189 & 3,085 \\
$N$ & 879 & 1,158 & 858 & & \\
\hline
\end{tabular}

a Distribution of participants according to the number of candidate- or party-centric cues they used to guide their choice decision, as percentage of the total number of respondents

b Table entries are the percentage of respondents assigned to each prototype who relied on different voting cues when casting their ballot. Since participants could use several of the voting cues, percentages do not necessarily sum to 100

and Redlawsk (2006), who found that voters in complex choice situations will tend to adopt "intuitive" decision rules and to heavily lean on a limited number of elementary shortcuts to simplify the selection task. As follows from the description of the devices, the name of the first candidate was a more relevant cue among participants assigned to Prototype 2 and, to a lesser extent, to Prototype 3, than among those under Prototypes 1 and 4. Subjects using these latter two devices, on the other hand, resorted more frequently to parties' names and numbers than the rest. As noted before, Prototype 1 required voters to punch the official party numbers into the keypad to access the complete list of candidates, while the information about parties and candidates under Prototype 4 was presented in ascending numerical order. Also, the fraction of participants who guided their vote using the parties' logos was substantially lower among those assigned to Prototype 4 than between subjects using the other three prototypes. This is consistent with the fact that only Prototypes 1, 2 and 3 displayed the logos on the ballot.

The inspection of heuristic use patterns among the participants indicates that they responded primarily to those shortcuts that were more clearly highlighted by each device. However, there are some differences in this regard between subjects assigned to Prototypes 1, 2 and 4 and those under Prototype 3. The latter relied relatively less on candidate- or party-centric heuristics than those under the remaining three prototypes, and were instead more prone to base their vote on 
“other"-e.g., "nonheuristic"-information. ${ }^{14}$ As already mentioned, participants under Prototype 3 had to inspect a large number of ballots in order to actively try to identify and locate their preferred candidates, and many of them reported having to go through considerable work to do so. In such conditions, individuals typically find it difficult to execute coherent search strategies and political heuristics allow for little cognitive savings in practice, since voters still have to gather and process large amounts of information (Lau and Redlawsk 2006). Hence, citizens may be forced to adopt other strategies to simplify the decision-making process, settling for "good enough" rather than "the best" candidates, using ad-hoc rules to guide their vote, even making random choices or simply refraining from choosing at all (Mondak 1993; Lau and Redlawsk 2006). This is consistent with preliminary evidence about subjects' voting patterns obtained from the exit survey. ${ }^{15}$ More than $11 \%$ of the subjects using Prototype 3 stated that they were unable to cast a vote for their favorite candidate in any of the two elections analyzed, against less than $4.5 \%$ of those allocated to the remaining prototypes. In addition, the proportion of blank ballots under Prototype 3 reached $8.3 \%$ in the national election and $10.6 \%$ in the city race, at least twice as high as under any of the other devices.

In an electoral context characterized by parties and candidates that differed substantially in their name recognition and in the level of public attention they drew during the campaign, the availability and prominence of specific cues associated with different voting technologies might have consistently benefitted some parties at the expense of others. We are mainly-though not only-interested in testing for systematic differences in the parties' vote-shares under Prototype 3 vis-à-vis each of the other three devices. In so far as the ballot design and voting procedures under this prototype were quite similar to those used in the official election, such comparisons can provide valuable insights into the potential consequences of replacing the voting system currently in place with one of the other mechanisms under consideration by Argentina's electoral authorities.

Previous research indicates that party labels can have a substantial impact on voter choice, especially in low information races such as legislative elections (Schaffner and Streb 2002). In particular, major party cues will tend to be much more effective as heuristic aids than minor party cues (Coan et al. 2008). Hence, our first hypothesis (H.1) states that Prototypes 1, 2 and 4 should have increased the vote-shares of ARI, FPV, and PRO, the parties with higher public prominence and larger campaign spending, vis-à-vis Prototype 3. While we expect the effect of the party-centric shortcuts highlighted by these three devices to have been significant in the two legislative races under study, their influence should have been more marked in the city election (H.2). As noted by Schaffner and Streb (2002), partisan heuristics are especially relevant in less salient and relatively unpublicized races in which there is little information about the candidates besides their party affiliation, as was the case of the election for the Buenos Aires legislature.

\footnotetext{
14 The differences in the relative influence of alternative voting cues across prototypes are significant at the usual confidence levels (Loughin and Scherer 1998).

15 See Table S.1 in the Supplementary Materials.
} 
Familiarity with candidates' names has also been shown to be a relevant determinant of electoral choice, to the extent that those who vote contrary to their partisan preferences usually do so in favor of the more renowned candidates (Wolak 2009). In this regard, the main difference between Prototype 2 and the "purely" party-centric devices-Prototypes 1 and 4-was that the former also underscored candidate-centric cues. Hence, our third hypothesis (H.3) states that Prototype 2 should have increased the vote-shares of the parties with easily recognizable candidates running for Congress relative to Prototypes 1 and 4 . In this sense, the popularity of Carrió, Bielsa and Macri might have contributed not only to further boost the vote for ARI, FPV and PRO under Prototype 2 vis-à-vis Prototype 3, but also compared to the technologies that only stressed party-centric information. In addition, the availability of candidate-centric cues should have benefitted smaller parties like AL, MFC and UPT as well. These parties' first candidates, Zamora, Casán and Bullrich, were notorious personalities in their own right, and were probably - certainly so in the case of media personality Moria Casán-more widely known and more easily identified by voters than the corresponding party labels. Thus, the support for these parties in the national election should have been considerably higher under Prototype 2 than under any of the two party-centric devices. We do not expect a significant effect of candidate-centric cues in the election of city legislators, though, since most of the candidates enjoyed no name recognition. Hence, Prototype 2 should not have improved the electoral chances of AL, MFC and UPT in the city race (H.4).

Finally, as discussed before, subjects under Prototype 3 faced a more complex information environment than the rest, and political heuristics played a less predominant role for them at the moment of deciding their vote. Hence, our fifth hypothesis (H.5) states that, comparing Prototype 3 to each of the other devices, we should see a reduction in the support for the parties more likely to be favored by these voting cues and, consequently, an increase in the vote-share of the other, lesser known parties presenting virtually anonymous candidates in both legislative races.

\section{Estimating the Effect of Different Voting Technologies on Election Outcomes}

Given our experimental design, simple tests for differences in means could in principle be used to assess the validity of the hypotheses formulated above (Ho et al. 2007). Nevertheless, randomization of participants across treatment groups balances their characteristics in expectation only, and thus the possibility of systematic variations in any observed sample remains. Accounting for these sample-specific differences is particularly important in the case of the Buenos Aires pilot, since equipment failures prevented setting up Prototypes 3 and 4 in all the experimental test sites, as originally planned. Only in 17 precincts were voters randomized between the four prototypes. In other 23 precincts, they were allocated to Prototypes 1, 2 and 3, while in 1 precinct only Prototypes 1 and 2 were tested. In addition, the number of eligible voters varied over precincts, and the amount of time needed to complete the vote oscillated across participants and machines. As a result, the fraction of subjects assigned to each prototype varied both within and between 
precincts, with roughly $30 \%$ of them allocated to each of the first three prototypes but less than $10 \%$ assigned to Prototype $4 .^{16}$ This could have led to significant differences in the characteristics of the participants using alternative technologies, potentially affecting the estimates of their impact on election results (Ho et al. 2007).

Table 2 presents descriptive statistics for all the pretreatment covariates for which information was obtained from the post-experimental surveys, discriminated by voting device. ${ }^{17}$ These variables aim at capturing differences in participants' cognitive ability, political sophistication, familiarity with technology and other background characteristics that might be correlated with their electoral preferences and/or their propensity to rely on heuristics (Schaffner and Streb 2002; Lau and Redlawsk 2006). As seen in the table, there was little variation in the characteristics of the subjects assigned to Prototypes 1,2 and 3. In contrast, differences in the distribution of the covariates between participants allocated to Prototype 4 and the rest tended to be larger. In particular, the fraction of participants with postsecondary education was significantly higher under Prototype 4, while the levels of political interest and the proportion of first-time voters were lower. ${ }^{18}$ To account for these differences, we combine parametric and non-parametric statistical methods to test hypotheses H.1-H.5.

Privacy considerations prevented us from linking the individual vote data obtained from the prototypes' log files with participants' responses to the survey questions. Therefore, we can only analyze the average characteristics of the subjects assigned to the different prototypes within each precinct. To do so, we defined 139 voting stations by 'crossing' the precincts with the number of prototypes tested in each of them and modeled the number of votes for the different parties in each voting station as a vector of counts (Mebane and Sekhon 2004). However, aggregate-level variables typically fail to capture traits that vary across voters within geographical units, some of which may affect vote choice probabilities. As a result, vote counts generally exhibit higher variability (over-dispersion) than the standard multinomial model for count data can account for, which might lead to underestimate the variance-covariance matrix and to draw incorrect conclusions about hypothesis tests and confidence intervals for the parameters of interest (Mebane and Sekhon 2004, Guimarães and Lindrooth 2007). To overcome this problem, we fit a Dirichlet-multinomial regression model to examine the relationship between the parties' vote-shares and the prototypes tested in the pilot, including the average characteristics of the participants in each voting station as additional controls. This allows for a simple and computationally efficient way of accommodating extra-multinomial variation even in the presence of large choice sets (Guimarães and Lindrooth 2007). ${ }^{19}$

\footnotetext{
16 Table S.2 in the Supplementary Materials reports the distribution of subjects by prototypes and precincts.

17 Table S.3 and Figure S.5 in the Supplementary Materials provide further details on the distribution of the covariates across prototypes.

18 Table S.4 in the Supplementary Materials summarizes the results from several covariate balance checks.

19 Section 4 in the Supplementary Materials describes the Dirichlet-multinomial regression model.
} 
Table 2 Descriptive statistics of relevant covariates across treatment groups

\begin{tabular}{llllll}
\hline Variable & $\begin{array}{l}\text { Prototype 1 } \\
\text { (party cues) }\end{array}$ & $\begin{array}{l}\text { Prototype 2 } \\
\text { (candidate and } \\
\text { party cues) }\end{array}$ & $\begin{array}{l}\text { Prototype 3 } \\
\text { (candidate cues, } \\
\text { little cognitive savings) }\end{array}$ & $\begin{array}{l}\text { Prototype 4 } \\
\text { (party cues) }\end{array}$ & Scale \\
\hline $\begin{array}{l}\text { Education levels }^{\mathrm{a}} \\
\quad\end{array}$ & & & & & \\
Primary $^{\mathrm{b}}$ or less $^{\mathrm{b}}$ & 0.08 & 0.07 & 0.07 & 0.04 & $0-1$ \\
Secondary $^{\mathrm{b}}$ & 0.31 & 0.30 & 0.31 & 0.27 & $0-1$ \\
Post-secondary $^{\mathrm{b}}$ & 0.61 & 0.62 & 0.62 & 0.68 & $0-1$ \\
Females $^{\mathrm{a}}$ & 0.54 & 0.55 & 0.53 & 0.55 & $0-1$ \\
First-time voters $^{\mathrm{a}}$ & 0.03 & 0.04 & 0.03 & 0.02 & $0-1$ \\
Interest in politics $^{\mathrm{c}}$ & 2.13 & 2.12 & 2.14 & 2.04 & $1-3$ \\
${\text { Older than } 50^{\mathrm{a}}}$ & 0.41 & 0.43 & 0.42 & 0.44 & $0-1$ \\
Political information $^{\mathrm{d}}$ & 2.07 & 2.05 & 2.06 & 2.06 & $0-3$ \\
Use of technology $^{\mathrm{e}}$ & 0.71 & 0.71 & 0.71 & 0.73 & $0-1$ \\
\hline
\end{tabular}

${ }^{a}$ As proportion of the participants assigned to each prototype

${ }^{\mathrm{b}}$ Complete or incomplete

c Coded on a three-point scale ranging from "not interested" (1) to "very interested" (3)

${ }^{d}$ Based on the number of correct responses to three political knowledge questions asking respondents the names of the Ministers of Education, Economics and Health

${ }^{e}$ Proportion of the participants who owned a personal computer and had regular internet access

In order to assess the sensitivity of the results to our modelling assumptions, we also implemented a non-parametric matching estimator based on Lechner (2001). This approach extends standard two-state (treatment versus non-treatment) matching methods for causal inference to the case of multiple unordered categorical treatments, and is thus particularly well suited for our application. ${ }^{20}$ The matching estimator avoids imposing distributional and functional form assumptions, although it relies on the-weaker-assumption that the potential treatment outcomes are independent of the assignment mechanism conditional on the voting station covariates (Lechner 2001). The parametric and non-parametric analyses have alternative strengths and weaknesses, and can thus be viewed as complementary rather than as substitutes (Herron and Wand 2007).

\section{Results}

Figure 3 reports pairwise differences in the expected vote-shares of the competing parties across prototypes, based on the estimates from the Dirichlet-multinomial model. $^{21}$

In line with our first hypothesis (H.1), the expected vote-share of ARI, FPV and PRO in the two legislative races increased by between 2.5 and 4.7 percentage points

\footnotetext{
${ }^{20}$ See Sect. 5 in the Supplementary Materials for additional details on the matching analysis.

${ }^{21}$ The estimates from the Dirichlet-multinomial model are presented in greater detail in Tables S.5-S.7 of the Supplementary Materials.
} 

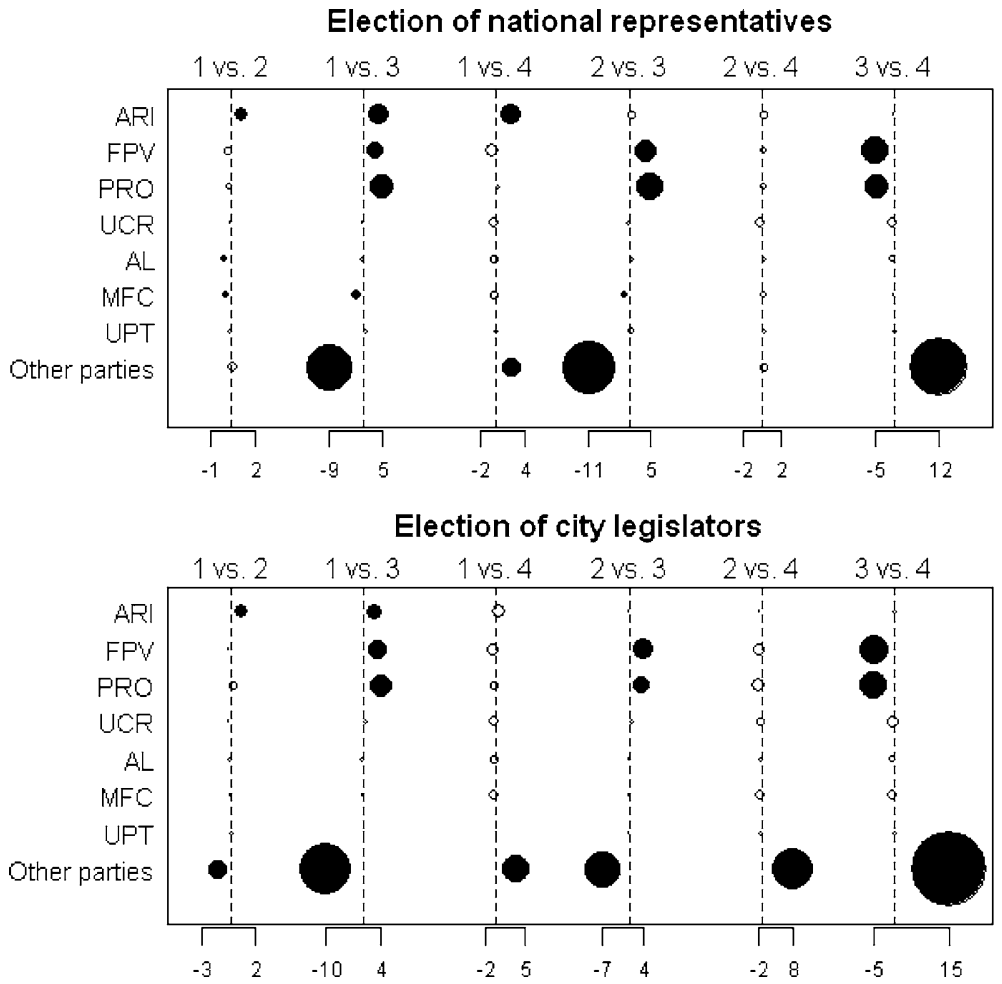

Fig. 3 Pairwise differential prototype effects estimated from the Dirichlet- multinomial regression model, in percentage points. The circles are proportional to the average differential effects on the support for each of the parties competing in the two legislative elections, with the solid dots marking those estimates that are significant at the usual confidence levels ( 0.9 and above). The dashed vertical lines correspond to a 0 percentage point change in the expected vote share of each party

under Prototype 1 relative to Prototype 3. Compared to the latter, Prototype 2 also raised the vote for FPV and PRO by more than 4 percentage points in the national election and by at least 2.8 points in the city race, while Prototype 4 increased their support by about 5 points in both elections. Although differences between these two devices and Prototype 3 were not significant for ARI at the usual confidence levels, the three major parties were still the only ones that consistently augmented their vote-shares under any of the prototypes highlighting partisan cues. Even for UCR, a traditionally important player in the Argentinean political scene that enjoyed considerably less media attention than ARI, FPV and PRO in 2005, priming voters on party-centric information did not lead to significant gains vis-à-vis Prototype 3. This result is in line with Bril's (2007) argument that, with the growing proportion of "uncommitted" citizens that depend primarily on the mass-media to obtain political information, media exposure and campaign advertising have become more relevant determinants of electoral success in Argentina than "old party politics". 
We do not find support for hypothesis H.2, though, since the impact of partycentric shortcuts on the vote for the three major parties in the two elections was statistically indistinguishable across races. ${ }^{22}$ The fact that the participants voted for city legislators after they had cast a ballot for national representatives probably increased the likelihood of choosing the same party in both elections and mitigated potential variations in the role of partisan heuristics. It is interesting to note that this held not only for Prototype 4, which clearly facilitated the recognition of parties between races, but also for both DRE devices.

Regarding our third hypothesis (H.3), the evidence is quite inconclusive. On the one hand, Prototype 2 did not significantly raise the expected vote-share of ARI, FPV and PRO in the national election compared to the "purely" party-centric Prototypes 1 and 4. Given the high levels of campaign spending and media exposure of these parties and the ample name recognition of Carrió, Bielsa and Macri, the availability of candidate-centric cues under Prototype 2 seems to have provided voters with little supplementary information. On the other hand, candidate priming did increase the support for AL and MFC by roughly 1 percentage point relative to Prototype 1, resulting in a 33\% jump in AL's vote-share and more than doubling the expected vote for MFC. The fact that these parties capitalized on the high name recognition of Zamora and Casán in the more visible election is also evident from the fact that, in the city race, differences in their support under Prototypes 1 and 2 were statistically insignificant. Thus, as stated in hypothesis H.4, the gains obtained by AL and MFC due to the prominence of their Congressional candidates did not spill over to the less salient election. However, even in the national race, the voteshares of AL and MFC under Prototype 2 were not higher than under Prototype 4.

Finally, consistent with our fifth hypothesis (H.5), the support for "Other parties" under Prototype 3 augmented by roughly 10 percentage points in the national election and by between 7 and 16 points in the city race compared to each of the other three devices. ${ }^{23}$ As expected, the difficulties experienced by users of Prototype 3 in guiding their choice by simple cognitive heuristics led to a distribution of votes that was less strongly concentrated around a few prominent parties and candidates than under the other prototypes, allowing the remaining contenders to capture substantially higher vote-shares.

As a robustness check, Fig. 4 in the Appendix presents the differential pairwise prototype effects obtained using Lechner's (2001) matching estimator. ${ }^{24}$ Although point estimates are not necessarily similar to those from the Dirichlet-multinomial model, the main substantive findings agree with those reported in Fig. 3. In the two races considered, prototypes that primed voters to rely on easily available political

\footnotetext{
22 In the case of Prototype 2, it is plausible that the stronger incidence of party-centric cues in the less visible election could have been countered by a larger impact of candidate-centric shortcuts in the election for Congress, thus concealing possible variations in the influence of partisan heuristics across races. However, even for the two "purely" party-centric Prototypes 1 and 4, differences in the vote-shares of ARI, FPV and PRO relative to Prototype 3 were not significantly higher in the election of city legislators.

23 These differences were all significant at the 0.01 level.

24 These nonparametric estimates are presented in greater detail in Table S.10 of the Supplementary Materials.
} 
heuristics consistently increased the vote for the three major parties, i.e., those parties with more campaign funds and more media presence. Some of the small parties featuring high-profile personalities also benefitted from candidate priming in the national election. However, the vast majority of the parties running modest campaigns and featuring little known candidates fared definitely better under the technology more similar to the current voting system, which required more taxing information processing efforts from the participants and downplayed the relative utility of candidate- and party-centric shortcuts.

The magnitude of the estimated prototype effects in the Buenos Aires pilot can be better appraised in the light of the results from the few studies assessing the impact of voting technologies on electoral outcomes in two-party systems. For instance, Card and Moretti (2007) found that the adoption of automated voting led to a marginally significant gain of $0.2-0.3$ percentage points in the Republican two-party vote-share between the 2000 and 2004 U.S. presidential elections. Other scholars, such as Herron and Wand (2007), failed to encounter any significant effect of voting technologies on election returns altogether. Compared to these analyses based on (observational) data from U.S. elections, our experimental results suggest that, in the case of elections with a very large number of parties that differ widely in the visibility of their labels and candidates, alternative voting technologies can lead to substantial variations in the relative support of the contenders.

To further illustrate this point, we conducted a counterfactual analysis based on the estimates from the Dirichlet-multinomial model, simulating the election results assuming only one prototype had been used in all the voting stations. Table 5 in the Appendix reports the parties' expected vote-shares in each of these scenarios, while Table 3 presents the corresponding distribution of legislative seats.

If Prototype 3 had been used in all the test sites, the vote for "Other parties" would have increased by more than 6 percentage points in the pilot, going from $28 \%$ in the national election and $39 \%$ in the city race to $36 \%$ and $45 \%$, respectively. On the other hand, the three larger parties would have gathered only $50 \%(44 \%)$ of the vote in the national (city) election versus the actual $61 \%(51 \%)$ they obtained in the experiment. Although these differences would not have altered the distribution of Congressional seats, they would have affected the representation of the parties in the city legislature, for which the seat allocation formula is more proportional and more sensitive to marginal changes in vote-shares than the one used to elect national representatives. ${ }^{25}$ As seen in Table 3, ARI, FPV and PRO would have obtained 22 of the 30 available seats under Prototypes 1, 2 and 4. In contrast, they would have captured only 20 seats under Prototype 3, with FPV and PRO losing 1 seat each to "Other parties". While the vote for ARI would also have decreased in this scenario

\footnotetext{
25 A PR-D'Hont formula is used in Buenos Aires to elect both national representatives and city legislators. However, the differences in district magnitudes and the fact that a party has to gather the support of more than $3 \%$ of the registered voters to achieve representation in Congress-but not in the city legislature-determines that seat allocation in the national election is less sensitive to marginal changes in relative vote-shares. See Calvo and Micozzi (2005) and the references therein for a description of Argentina's electoral rules.
} 
Table 3 Allocation of legislative seats under different electoral scenarios

\begin{tabular}{|c|c|c|c|c|c|c|c|c|c|c|c|c|}
\hline \multirow[t]{3}{*}{ Parties } & \multicolumn{6}{|c|}{ Seat allocation for national representatives (13) } & \multicolumn{6}{|c|}{ Seat allocation for city legislators (30) } \\
\hline & \multicolumn{4}{|c|}{ Prototypes $^{\mathrm{a}}$} & \multirow{2}{*}{$\begin{array}{l}\text { Pilot } \\
\text { election }^{\mathrm{b}}\end{array}$} & \multirow{2}{*}{$\begin{array}{l}\text { Official } \\
\text { election }^{\mathrm{c}}\end{array}$} & \multicolumn{4}{|c|}{ Prototypes $^{\mathrm{a}}$} & \multirow{2}{*}{$\begin{array}{l}\text { Pilot } \\
\text { election }\end{array}$} & \multirow{2}{*}{$\begin{array}{l}\text { Official } \\
\text { election }^{\mathrm{c}}\end{array}$} \\
\hline & 1 & 2 & 3 & 4 & & & 1 & 2 & 3 & 4 & & \\
\hline ARI & 4 & 4 & 4 & 4 & 4 & 4 & 8 & 7 & 8 & 7 & 8 & 8 \\
\hline FPV & 3 & 3 & 3 & 3 & 3 & 3 & 5 & 6 & 4 & 6 & 5 & 7 \\
\hline PRO & 4 & 4 & 4 & 4 & 4 & 6 & 9 & 9 & 8 & 9 & 9 & 13 \\
\hline UCR & 1 & 1 & 1 & 1 & 1 & - & 2 & 2 & 2 & 2 & 2 & - \\
\hline $\mathrm{AL}$ & - & - & - & - & - & - & 1 & 1 & 1 & 1 & 1 & 1 \\
\hline MFC & - & - & - & - & - & - & - & - & - & - & - & - \\
\hline UPT & - & - & - & - & - & - & 1 & - & 1 & 1 & 1 & - \\
\hline Other parties ${ }^{\mathrm{d}}$ & 1 & 1 & 1 & 1 & 1 & - & 4 & 5 & 6 & 4 & 4 & 1 \\
\hline \multicolumn{13}{|c|}{ a Based on the parties' simulated vote-shares in the different electoral scenarios } \\
\hline \multicolumn{13}{|c|}{${ }^{\mathrm{b}}$ Seat allocation based on the actual pilot election results } \\
\hline \multicolumn{13}{|c|}{${ }^{c}$ Seat allocation in the official election } \\
\hline \multicolumn{13}{|c|}{$\begin{array}{l}\text { The seat assigned to "Other parties" in the simulated Congressional election corresponds to the } \\
\text { Socialist Party, the only party whose expected vote-share would exceed the } 3 \% \text { threshold required to } \\
\text { obtain a seat in Congress according to the Argentine electoral law. In the case of the city race, } 4 \text { minor } \\
\text { parties (Socialist Party, Partido Humanista, Partido Socialista Autentico and Movimiento Socialista de } \\
\text { los Trabajadores) would achieve representation in the Buenos Aires legislature }\end{array}$} \\
\hline
\end{tabular}

(see Table 5 in the Appendix), the redistribution of seats would have left this party with as many legislators as the actual election winner, PRO.

Interestingly, political actors' perceptions about the partisan advantages determined by the different technologies run counter to the empirical evidence presented here. In recent years, ARI has advocated for a radical change in voting procedures but, according to the pilot's results, the party would be relatively better off under the prototype most similar to the current system (Prototype 3). In contrast, FPV has strongly opposed the introduction of a single ballot listing the information for all the parties, which is the main feature of Prototype 4, the voting device that would have maximized its expected support in the two elections analyzed (Table 5 in the Appendix). Anecdotal evidence from countries switching to new voting systems suggests that parties may learn to adjust to changes in voting procedures, adapting their electoral and campaign communication strategies to the particular technology used. ${ }^{26}$ An in-depth analysis of how political elites react to the introduction of new

\footnotetext{
${ }^{26}$ For instance, in Brazil, the first country in the world to conduct fully electronic elections, the adoption of new technologies has introduced some changes in parties' campaign advertising tactics. In particular, the substitution of paper ballots that allowed voters to write the names of their preferred candidates to mark their preferences by voting machines that only allow them to type the candidates' registration numbers has led parties to heavily publicize these numbers during the electoral season.
} 
voting technologies, a topic that has deserved hardly any academic interest despite its potentially relevant implications, is left for future research.

\section{Concluding Remarks}

Despite growing academic interest in new voting technologies (Alvarez and Hall 2008; Herrnson et al. 2008), few studies have examined their effect on election results. In this paper, we present the first analysis of the potential impact of alternative voting systems on electoral outcomes in multiparty races, focusing on the information effects embedded in different electronic machines tested in a largescale voting pilot conducted during the 2005 Buenos Aires legislative election. Our research design overcomes many of the problems that have plagued previous observational studies in this area, and our statistical approach combines parametric and non-parametric methods to account for differences in the composition of the treatment groups and to assess the robustness of the main findings.

The results from our experiment indicate that the type of information highlighted by different technologies and the form in which it is presented might have a significant influence on voter behavior. Prototypes that allowed subjects to simplify their choice by focusing only on easily available candidate-and party-centric shortcuts systematically favored those parties with higher campaign spending and media presence, more recognizable labels and/or more renowned candidates. In contrast, the electoral chances of lesser known candidates and parties improved under the device that made it more difficult for individuals to rely exclusively on political heuristics and forced them to adopt alternative decision-making strategies. Our findings were less conclusive about the impact of particular voting cues. Contrary to our expectations, we did not find clear differences in the effect of candidate and party priming across races. While some authors have argued that political heuristics play a more relevant role in less salient and relatively unpublicized elections, our results suggest that their influence may depend considerably on the complexity of the decision environment and on the characteristics of the competing parties, pointing to the need for further research in this area. Future work should also examine how political elites react to differences in cognitive demands across voting systems, and whether and to what extent these differences influence parties' electoral strategies.

Overall, the evidence presented in this paper shows that researchers analyzing the implications of changes in voting technology should focus not only on the prospective gains in the efficiency of election administration and on the reduction in voting errors, but also on their impact on election outcomes. As illustrated by the analysis of the Buenos Aires pilot, certain technologies may in fact shape election results, rather than merely record voters' preferred choices. In a context in which the need for cognitive savings was substantially increased due to the overwhelming amount of information voters were exposed to, the variations in election returns across voting devices were considerably larger than had been previously recorded in two-party races. Even though caution should be exerted when extrapolating our conclusions to different settings, we hope that our results will encourage scholars 
and election authorities in other countries implementing reforms in their voting procedures to pay particular attention to the potential partisan advantages induced by alternative technologies. In this direction, our findings underscore the importance of comparing not only traditional and electronic voting methods, but also different automated voting systems. While this might be quite apparent in the U.S. given the wide variety of voting procedures used, it is definitely not the case in other regions (Europe, Latin America) where the debate has centered almost exclusively on the opposition between "paper ballots" and "voting machines".

\section{Appendix}

See Tables 4, 5 and Figure 4.

Table 4 Socio-demographic characteristics of the experimental subjects and of the electorate

\begin{tabular}{|c|c|c|}
\hline Variable & $\begin{array}{l}\text { Participants } \\
\text { in the pilot }\end{array}$ & $\begin{array}{l}\text { Population of } \\
\text { eligible voters }\end{array}$ \\
\hline Average age (in years) & 46.66 & 46.35 \\
\hline Younger than $30(\%)$ & 18.51 & 25.07 \\
\hline Older than $50(\%)$ & 42.31 & 39.81 \\
\hline Females (\%) & 54.30 & 55.84 \\
\hline \multicolumn{3}{|l|}{ Education level (\%) } \\
\hline No education & 0.11 & 0.51 \\
\hline Primary, incomplete & 0.58 & 2.97 \\
\hline Primary, complete & 6.36 & 15.56 \\
\hline Secondary, incomplete & 6.13 & 11.44 \\
\hline Secondary, complete & 24.40 & 20.19 \\
\hline Post-secondary, incomplete ${ }^{\mathrm{b}}$ & 17.44 & 21.00 \\
\hline Post-secondary, complete ${ }^{\mathrm{b}}$ & 44.98 & 28.32 \\
\hline Total number of voters & 13,876 & $174,846^{\mathrm{c}}$ \\
\hline
\end{tabular}

\footnotetext{
${ }^{a}$ Information on the socio-demographic characteristics of the electorate in the precincts in which the pilot was conducted was obtained from the National Institute of Statistics and Censuses of Argentina (INDEC)

${ }^{\mathrm{b}}$ Post-secondary education comprises University and professional/technical training

${ }^{c}$ Number of citizens who actually cast an official ballot in the precincts in which the pilot test was conducted. This constituted our potential subject pool
} 


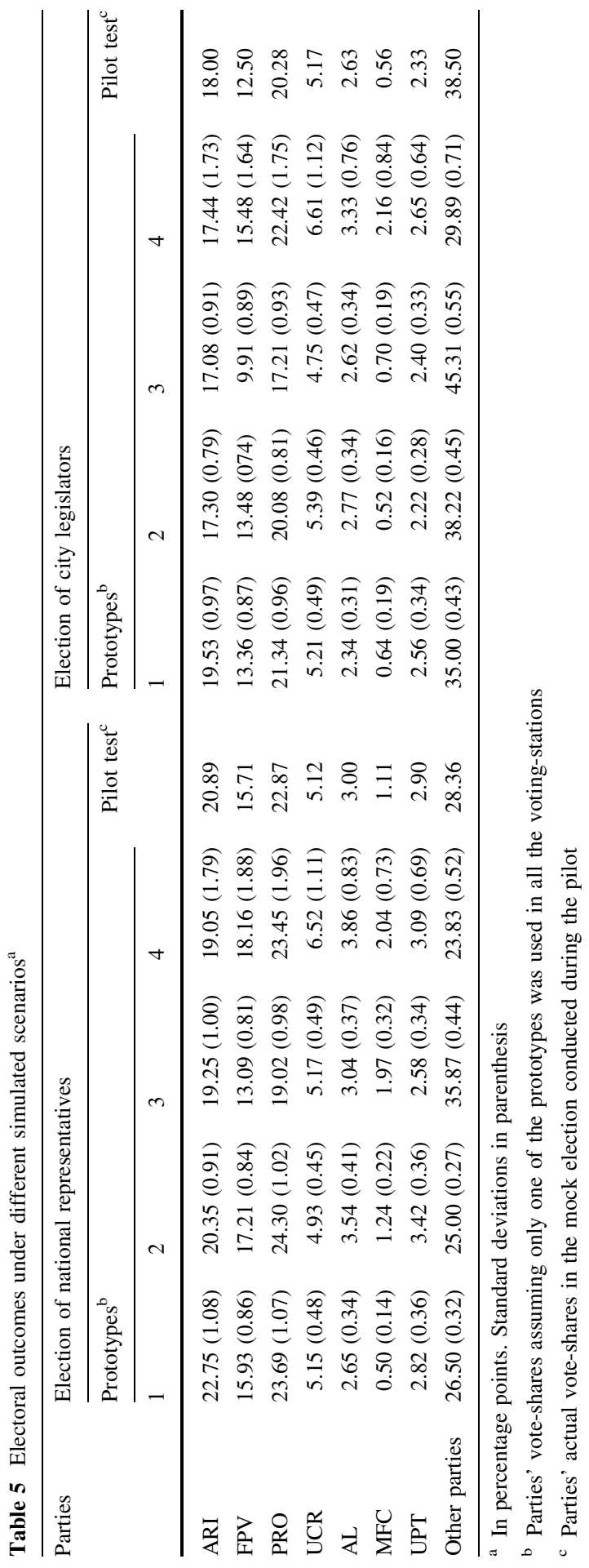



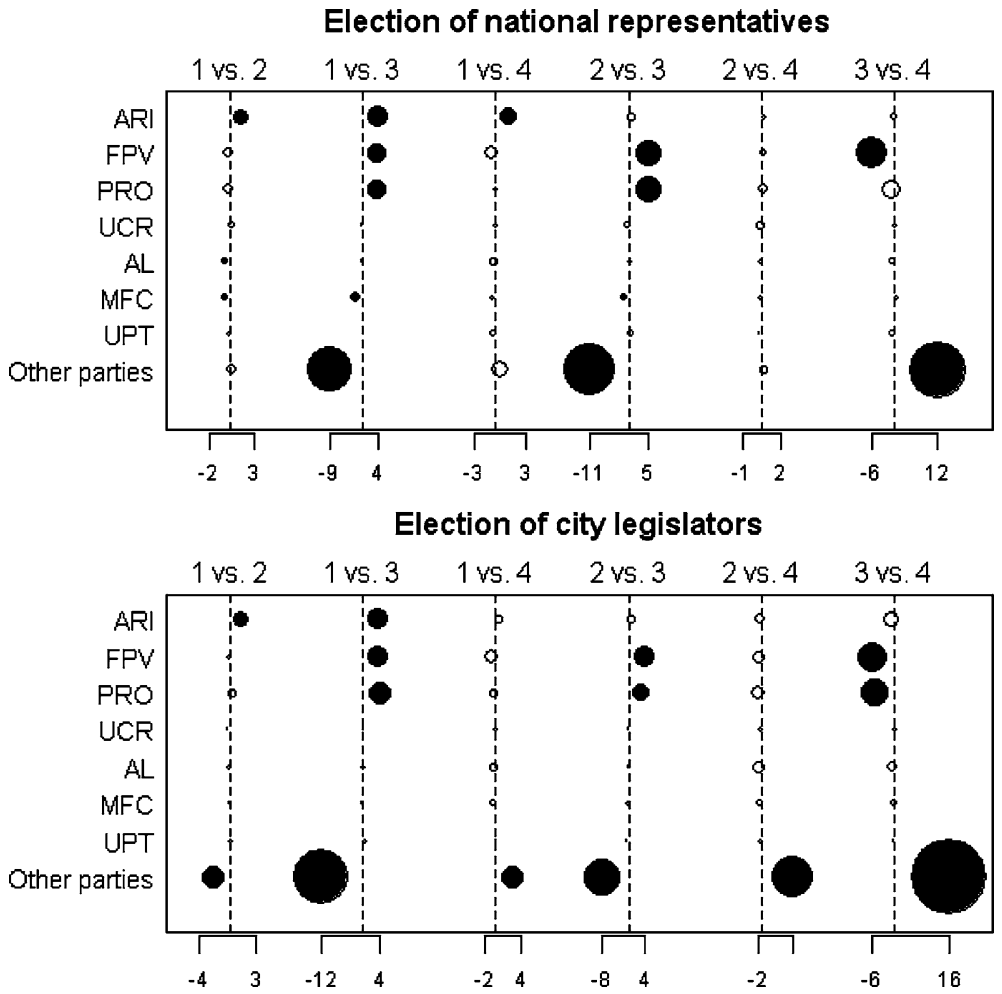

Fig. 4 Nonparametric estimates of the pairwise differential prototype effects, in percentage points. The circles are proportional to the average differential effects on the support for each of the parties competing in the two legislative elections, with the solid dots marking those estimates that are significant at the usual confidence levels ( 0.9 and above). The dashed vertical lines correspond to a 0 percentage point change in the expected vote share of each party

\section{References}

Alvarez, R. M., \& Hall, T. E. (2008). Electronic elections: The perils and promises of digital democracy. Princeton: Princeton University Press.

Alvarez, R. M., Katz, G., \& Pomares, J. S. (2009). Up to the promise? The impact of electronic voting on trust in the election process in Latin America. Working Paper 89, Caltech/MIT Voting Technology Project.

Amado, A. (2006). Argentina 2005: Repensar la comunicación política. Diálogo Político, 2, 49-77.

Ansolabehere, S., \& Stewart, C., III. (2005). Residual votes attributable to technology. Journal of Politics, $67,365-389$.

Bartels, L. M. (1996). Uninformed votes: Information effects in presidential elections. American Journal of Political Science, 40, 194-230.

Bril, T. (2007). El colapso del sistema partidario de la Ciudad de Buenos Aires. Una herencia de la crisis argentina de 2001-2002. Desarrollo Económico, 47, 367-400.

Buenos Aires Controller's Office, AGCBA (2006). Informe de Auditoría - Gastos de Campaña 2005. Technical Report, February 2006.

Calvo, E., Escolar, M., \& Pomares, J. S. (2009). Ballot design and split ticket voting in multiparty systems: Experimental evidence on information effects and vote choice. Electoral Studies, 28, 218-231. 
Calvo, E., \& Micozzi, J. P. (2005). The governor's backyard: A seat-vote model of electoral reform for subnational multiparty races. Journal of Politics, 67, 1050-1074.

Card, D., \& Moretti, E. (2007). Does voting technology affect election outcomes? Touch-screen voting and the 2004 presidential election. Review of Economics and Statistics, 89, 660-673.

COPUB, Centro de Opinión Pública de la Universidad de Belgrano. (2005). Elecciones legislativas 2005: valoración que los ciudadanos realizan del proceso electoral. http://www.ub.edu.ar/centros_de_ estudio/copub/. Accessed 8 February 2010.

Coan, T. G., Merolla, J. L., Stephenson, L. B., \& Zechmeister, E. J. (2008). It's not easy being green: Minor party labels as heuristic aids. Political Psychology, 29, 389-405.

Guimarães, P., \& Lindrooth, R. C. (2007). Controlling for overdispersion in grouped conditional logit models: A computationally simple application of Dirichlet-multinomial regression. Econometrics Journal, 10, 439-452.

Herrnson, P. S., Niemi, R. G., Hanmer, M. J., Bederson, B. B., \& Conrad, F. C. (2008). Voting technology: The not-so-simple act of casting a ballot. Washington, DC: Brookings Institution Press.

Herron, M. C., \& Wand, J. N. (2007). Assessing partisan bias in voting technology: The case of the 2004 New Hampshire recount. Electoral Studies, 26, 247-261.

Ho, D. E., Imai, K., King, G., \& Stuart, E. A. (2007). Matching as nonparametric preprocessing for reducing dependence in parametric causal inference. Political Analysis, 15, 199-238.

Lau, R., \& Redlawsk, D. P. (2006). How voters decide. Information processing during election campaigns. New York, NY: Cambridge University Press.

Lechner, M. (2001). Identification and estimation of causal effects of multiple treatments under the conditional independence assumption. In M. Lechner \& F. Pfeiffer (Eds.), Econometric evaluation of labour market policies (pp. 43-58). Heidelberg: Physica.

Levitt, S. D., \& List, J. A. (2007). What do laboratory experiments measuring social preferences tell us about the real world? Journal of Economic Perspectives, 21, 153-174.

Loughin, T. M., \& Scherer, P. N. (1998). Testing for association in contingency tables with multiple column responses. Biometrics, 54, 630-637.

Management Press. (2005). Informe cuantitativo audio-visual. Elecciones 2005. http://www.management press.com.ar. Accessed 15 October 2008.

Mebane, W. R., \& Sekhon, J. S. (2004). Robust estimation and outlier detection for overdispersed multinomial models of count data. American Journal of Political Science, 48, 391-410.

Mondak, J. J. (1993). Public opinion and heuristic processing of source cues. Political Behavior, 15, 167-192.

Popkin, S. L. (1991). The reasoning voter: Communication and persuasion in presidential campaigns. Chicago: University of Chicago Press.

Reynolds, A., \& Steenbergen, M. (2006). How the world votes: The political consequences of ballot design, innovation and manipulation. Electoral Studies, 25, 570-598.

Schaffner, B. F., \& Streb, M. J. (2002). The partisan heuristic in low-information elections. Public Opinion Quarterly, 66, 559-581.

Tomz, M., \& Van Houweling, R. P. (2003). How does voting equipment affect the racial gap in voided ballots? American Journal of Political Science, 47, 46-60.

Wolak, J. (2009). The consequences of concurrent campaigns for citizen knowledge of congressional candidates. Political Behavior, 31, 211-229. 